\title{
Humanizar las relaciones con la familia:
}

\section{la entrevista Spínola}

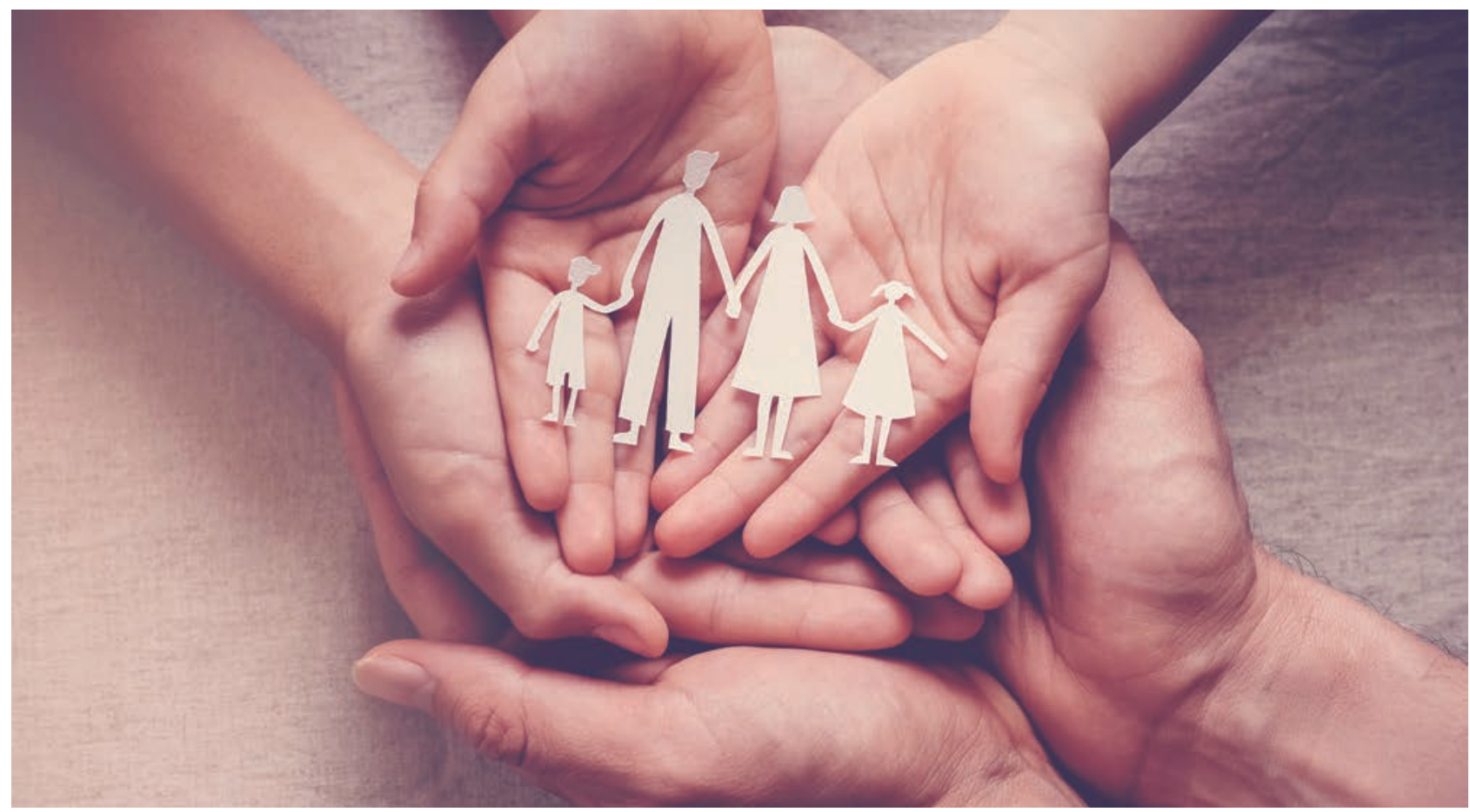

La entrevista en la escuela puede ser un espacio privilegiado para construir una relación de colaboración con las familias. Orientarnos al bien de cada hijo/alumno supone crear un espacio de confianza y seguridad tal, que cada uno de los que participamos en ella podamos sentir que seremos cuidados y que, en lo que comuniquemos y aportemos, encontraremos un nuevo relato que nos ayude a afrontar las

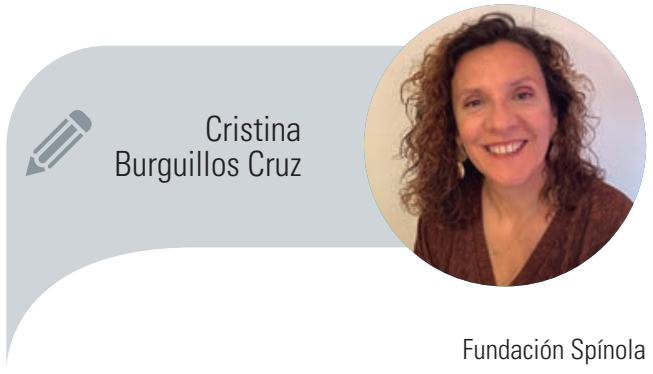
cristina.burguillos@fundacionspinola.es (ycburguilloscruz situaciones problemáticas.

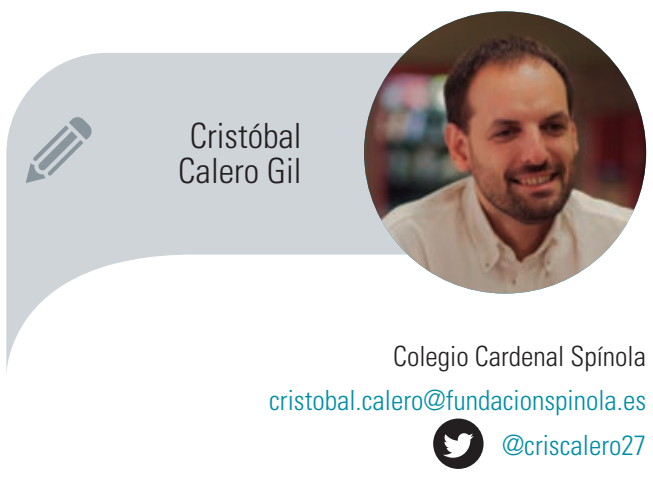




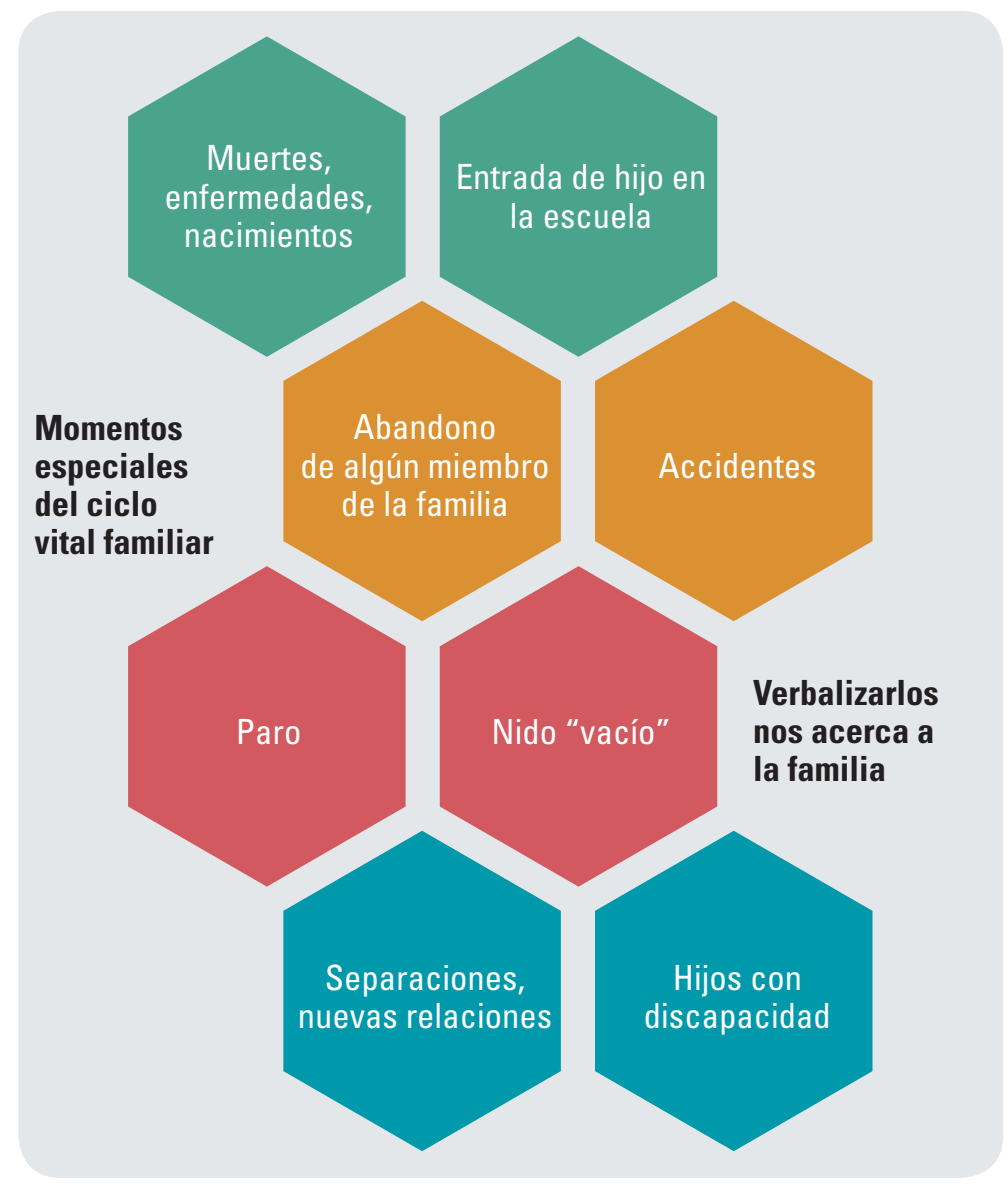

\section{La "experiencia del usuario"}

"Yo nunca fui a una tutoría, pero cada vez que había alguna después siempre había bronca"; "Mis padres volvían siempre enfadados"; "Parece que vas a que te examinen y te digan todo lo que tienes que hacer, pero tú sabes cómo es - te lo cuentan tus hijos y sus amigos-y lo único que te importa es si quiere a tu hijo. De otro modo es difícil escucharle"; "Los padres acaban siempre echando la responsabilidad de lo que no funciona sobre nosotros".

Así podríamos continuar construyendo líneas y líneas de experiencias de alumnos, familias y educadores con respecto a la relación que se establece en la entrevista con las familias por parte de las escuelas. Parece ser que existe un conflicto de percepciones, intenciones e intereses entre la escuela y las familias que, sin embargo, contrasta con la clara constancia de que ambas trabajan por el mismo objetivo: el bien de cada alumno o hijo. Abordaremos, pues, una forma de relacionarnos como escuela entre los tres agentes más esenciales que la componen (alumnos, educadores y fami- liares) que permita aprovechar este privilegiado espacio como un elemento de construcción.

\section{Lo que ocurre en una entrevista familiar}

Cuando abordamos una entrevista familiar debemos estar muy atentos al juego de roles, jerarquías y relaciones que se ven expuestos en ella. Nuestro estilo de comunicación, nuestra conciencia del mundo emocional que se genera detrás de una reunión tan delicada, nuestra propia conciencia del rol de cada uno y de los riesgos que emergen de esta situación puede ayudarnos a limitar enormemente la posibilidad de que se produzcan daños indeseados. Involuntariamente hemos creado un escenario en el que parecemos estar abocados al malentendido y al refuerzo de las propias posturas. Puede que no exista ningún enemigo mayor del cambio, el crecimiento y la trasformación que este.

Nosotros proponemos una forma de abordarla que nos permita "dejar de hablar en idiomas distintos" cuando nos relacionamos en la escuela.

\section{Distintas situaciones familiares actuales}

La creciente diversidad de estructuras familiares, la progresiva reducción de espacios naturales de crecimiento para los niños (recluidos en sus habitaciones, videojuegos, ordenadores...), la reducción de la natalidad acompañada de la cada vez mayor sobreprotección de la infancia..., la precariedad laboral, la dificultad de emancipación de los jóvenes, la necesidad de cuidar a los ancianos...

Configurar hoy una familia es toda una aventura no exenta de riesgos y miedos. Estas emociones siempre nos acompañan, también cuando acudimos a una entrevista en el colegio de nuestro hijo.

\section{El iceberg (lo que se ve, lo que no se ve)}

Por más que queramos naturalizar el momento de una entrevista familiar, no deja de ser una situación delicada en la 
que debemos ajustarnos lo mejor posible. Aun así, nunca actuaremos en ella como lo hacemos en la cafetería, en la piscina o en el trabajo... si no somos muy conscientes de lo artificial de este acto, rápidamente la entrevista puede convertirse en una "estresvista".

Ni en el mejor de los casos, ni en la mejor de las entrevistas, llegaremos a conocer todo lo que hay detrás de lo que vemos. Igual que nos pasa con las personas, solo podemos acceder a la punta del iceberg de todas las dinámicas que puedan, en lo profundo, explicar las cosas que nos preocupan.

\section{Nuestra fundamentación El enfoque sistémico}

Nuestro marco fundamental de reflexión nos lo ha aportado el enfoque sistémico de las relaciones humanas. Este enfoque trata de complementar las limitaciones a las que el enfoque científico - basado en la observación y estudio de la realidad a través de la causalidad lineal- se enfrenta para definir y prever contextos ambiguos y complejos. Propone un enfoque diferente para observar fenómenos que no parecen funcionar con patrones lineales, en los que la mayor influencia la tienen los contextos y las relaciones que establecen todas las partes de esos contextos. Al igual que ocurre en la naturaleza y en la cibernética, todos los elementos que viven inmersos en sistemas están sujetos a formas de relación circulares, en las que todos los elementos están relacionados entre sí, todos influyen en todos y las causas no son independientes de los efectos, pues todo se encuentra interrelacionado. Así, las conductas de las personas se explican mejor a través de los contextos donde ocurren que a través de condiciones personales o previas (como la inteligencia, las habilidades, emociones...).

Lo que nos interesa de los sistemas es cómo funcionan, para así buscar evolucionar hacia formas de relación que permitan resolver las dificultades o encontrar las soluciones.
Principios sistémicos del orden

RECIPROCIDAD (do ut des)

Reciprocidad entre el dar y tomar. Fruto del buen convivir

PRIORIDAD DEL MIEMBRO MÁS ANTIGUO

Cada persona ocupa el lugar que le corresponde

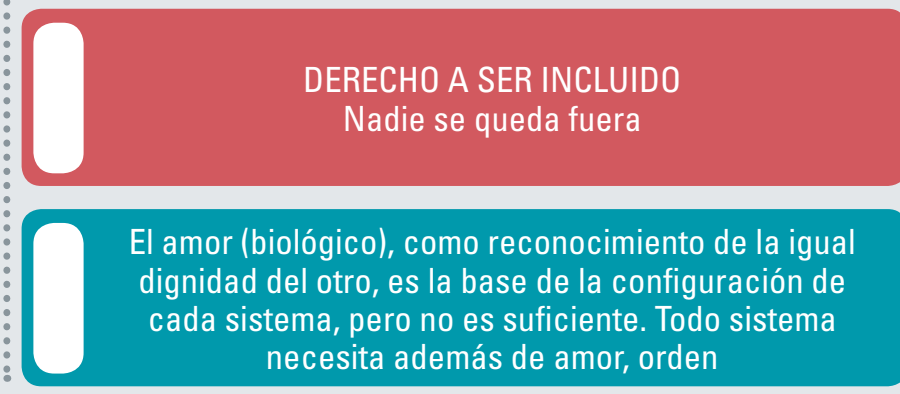

\section{Principios sistémicos}

Existen multitud de elementos que, desde la mirada sistémica, podemos tener en cuenta para ganar lucidez en los contextos en los que familias y educadores se encuentran:

$\boldsymbol{\lambda}$ La mirada al sistema: todo sistema tiene una estructura, una forma de relacionarse y se encuentra en determinado momento de su ciclo vital.

$\boldsymbol{7}$ Las "leyes" del sistema: siempre que somos o pretendemos ser parte de un sistema, de manera espontánea e inopinada, tenemos una tendencia a asegurarnos que todo va bien. Esta intuición, en cierto modo atávica, está siempre presente y validándose en todas nuestras interacciones. Así, tenemos una gran intuición desarrollada para evaluar nuestra pertenencia, si ocupamos el lugar que nos corresponde y si lo que aportamos al sistema es recíproco.

\section{Una cultura restaurativa}

Una de las experiencias con mayor impacto que hemos conocido y aplicado en nuestra tarea, y que nos ha permitido explorar con más profundidad sus aportaciones en el ámbito de la entrevista familiar, ha sido la cultura restaurativa (Albertí y Pedrol, 2017). Este movimiento, de claros principios sistémicos y que, a través de círculos comunicativos busca construir 


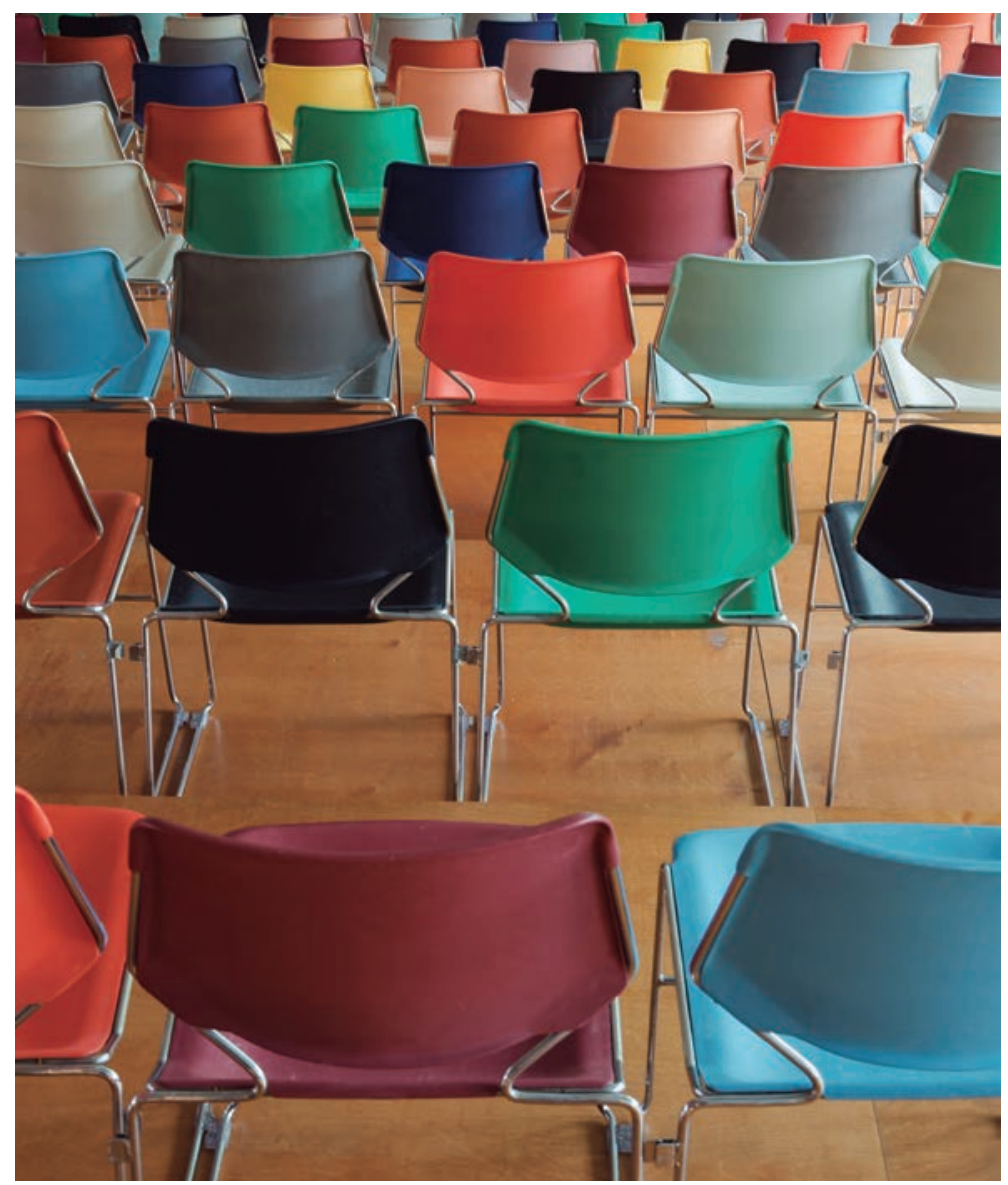

más y mejor comunidad, así como restaurar la conflanza de los miembros, se ha revelado como una herramienta muy eficaz, cuidadosa y respetuosa.

\section{Un enfoque comunicativo}

Siempre estamos comunicando. Todo acto humano comunica. Sin embargo, solo a veces, la comunicación es un acto explícito e intencional. Resulta muy necesario ser conscientes de que todo lo que hacemos comunica, más aún a quien acude a nuestro centro educativo, y de quien somos anfitriones, temerosos de que algo pueda ir mal o de recibir noticias desagradables. Los espacios, las miradas, los gestos, los tiempos, la actitud... están continuamente metacomunicando lo que somos y lo que queremos lograr en ese contacto.

\section{Aprendizaje dialógico}

El aprendizaje dialógico se basa en una concepción comunicativa del aprendizaje entendiendo que las personas aprendemos en la interacción con otros en cualquier espacio vital. Este marco de referencia nos permite aportar los princi- pios del diálogo igualitario, la igualdad en la diferencia y la creación de sentido a la entrevista familiar (Aubert et al., 2008).

\section{Planificación centrada en la persona}

Este proceso (O’Brien, 2003) nos invita a pensar qué limitaciones o barreras encontramos en cada contexto en el que vive y se desarrolla el alumno y nos ofrece una metodología específica apoyada con herramientas concretas para la reflexión colaborativa: línea de vida, mapa de relaciones, sueños del alumno, DAFO, plan de futuro, cuaderno de acuerdos, etc.

\section{Preparando la entrevista}

En nuestro centro este es un tiempo compartido no solo por las personas que van a acudir a la entrevista, sino también por otros educadores, orientadores...

Es un tiempo definido, al que se le busca un hueco real donde acostumbramos a trabajar haciéndonos preguntas de este tipo:

$\boldsymbol{\lambda}$ ¿Cómo estoy yo respecto a esta entrevista?

خ ¿Qué puntos fuertes visualizamos en el desarrollo personal, social, académico del alumno?

त ¿Qué ha sido lo mejor en este último periodo?

入 ¿Qué nos preocupa? ¿Qué vemos mejorable?

入 ¿Qué nos gustaría conseguir al finalizar la entrevista?

入 ¿Qué emoción nos ayudaría vivir de manera auténtica?

入 ¿Cómo abordar los temas difíciles?

Concretamos también cuáles serán, a "modo de borrador", los pasos a seguir y qué educadores dinamizarán cada paso.

\section{Una ruta para desarrollar la entrevista}

Cada uno de estos pasos requiere conocimiento por parte de toda la comunidad educativa, así como tomar conciencia del valor de cada pequeña parte para que, como en una buena melodía, todo suene con un sentido completo. 
¡La web Xcelence.es

ya está disponible para

todos los centros

educativos de

España!
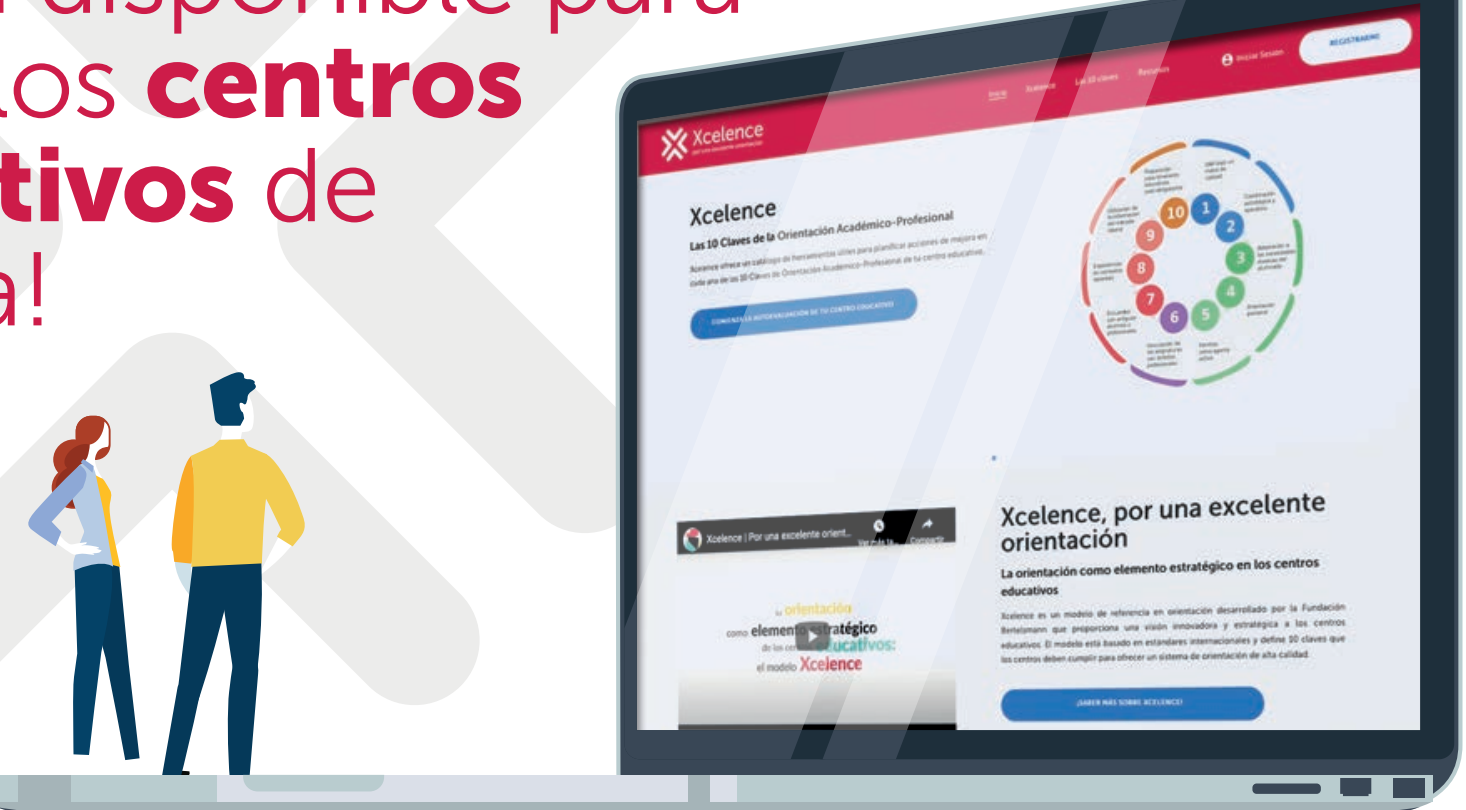

Xcelence es un modelo de referencia en orientación desarrollado por la Fundación Bertelsmann, que proporciona una visión innovadora y estratégica a los centros educativos.

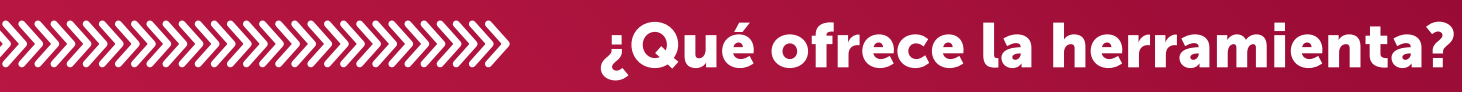

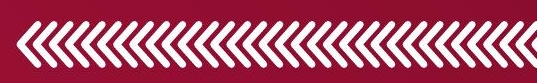

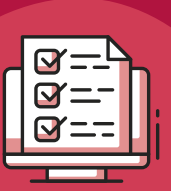

Autoevaluación online

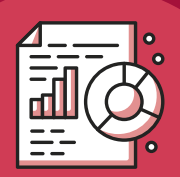

Diagnóstico personalizado

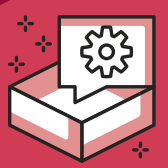

Recursos

y recomendaciones

Accede gratuitamente a través de www.xcelence.es. 


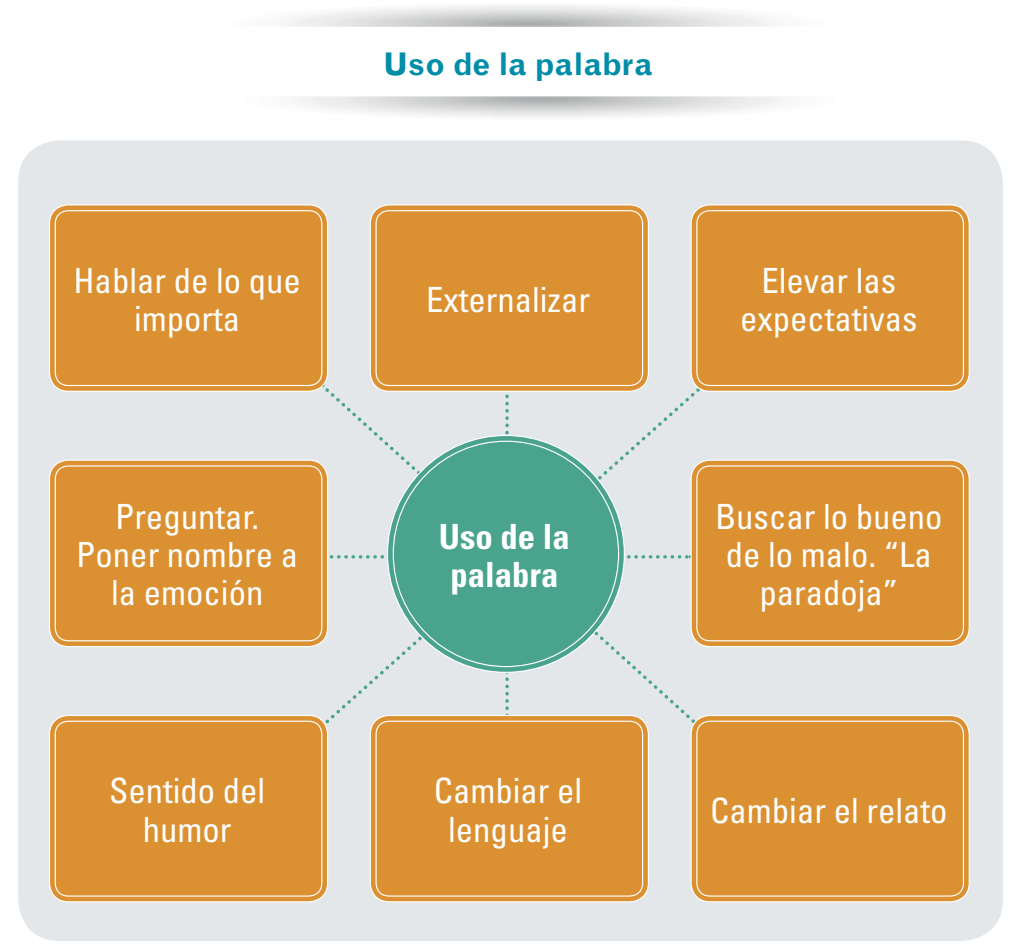

\section{Convocatoria}

En la mayoría de los centros tenemos algunos hábitos para las convocatorias de las entrevistas (desde la nota en la agenda, hasta una llamada telefónica, e-mail...) que facilitan y orientan tanto a la familia como a los educadores.

El primer convocado siempre es el alumno, y de forma general siempre invitamos a los progenitores o tutores del alumno.

\section{Acogida}

Todo proceso tiene un "hacer" que valida las mejores intenciones, esto es lo que nos ocurre en relación a la acogida inicial en una entrevista. Tenemos sensación de "cruzar un límite". Los seres humanos, por el principio de primacía y recencia, sabemos que tenemos más posibilidades de guardar en la memoria lo que ocurre al inicio y al final de las experiencias. Alguien tiene que asumir el rol de anfitrión y conviene definirlo siempre de forma previa.

Sobre el espacio hay mucho que decir. Solo apuntar aquí que el lugar debe al menos "decirnos" que es propicio para la conversación, la intimidad y la confianza.

\section{Cómo comenzar}

Crear un espacio emocional seguro para todos es nuestra prioridad. Para esto nos ayudamos de cuatro claves:
- Mirar a la persona.

त Mirar el rol de cada uno.

त Mirar la totalidad, el "sistema".

$\boldsymbol{\lambda}$ Mirar al equipo.

En coherencia con todo lo anterior, y en base a nuestra propia experiencia, el agradecimiento siempre es el comienzo. No es una fórmula de cortesía, es dar gracias a cada uno de forma personalizada, también a nuestro alumno y a los educadores del centro que participan.

\section{Entrando en lo que importa}

Podríamos decir que esta es una fase "espiral", de fuera a dentro... como que va llegando desde lo global a espacios más profundos y comprometidos, dependiendo de la problemática que tratemos.

Primero conectamos con las expectativas de todos. Tenemos que recoger lo que trae la familia y la emoción en la que nos encontramos. En una primera fase siempre nos enfocamos en las "buenas noticias", en aquello que es punto fuerte - satisfacción. Después entramos más a fondo con cuestiones del tipo ¿qué nos preocupa a cada uno? ¿Desde cuándo ocurre? ¿Qué soluciones hemos intentado? ¿Cuándo no sucede? ¿Qué cosas pasan cuando no sucede?

Ahora es el momento de visualizar el éxito y automotivarnos con la tarea, ¿qué notarían los compañeros de mi clase?, ¿qué pasaría en las comidas de casa?, ¿qué hábitos habría conseguido? Podemos construir y verbalizar un nuevo relato con la visión de todos. De aquí se deducen fácilmente algunas metas sencillas, centradas en los pequeños cambios a realizar por parte de cada uno.

\section{Cuidar el cierre}

Es el momento de la síntesis tanto del contenido del proceso y de las emociones vividas. Es muy importante escuchar cómo nos vamos cada uno y devolver el agradecimiento a todo el equipo, cuidar especialmente una palabra cariñosa si alguna persona ha estado muy involucrada o bien ha pasado algún momento malo. 


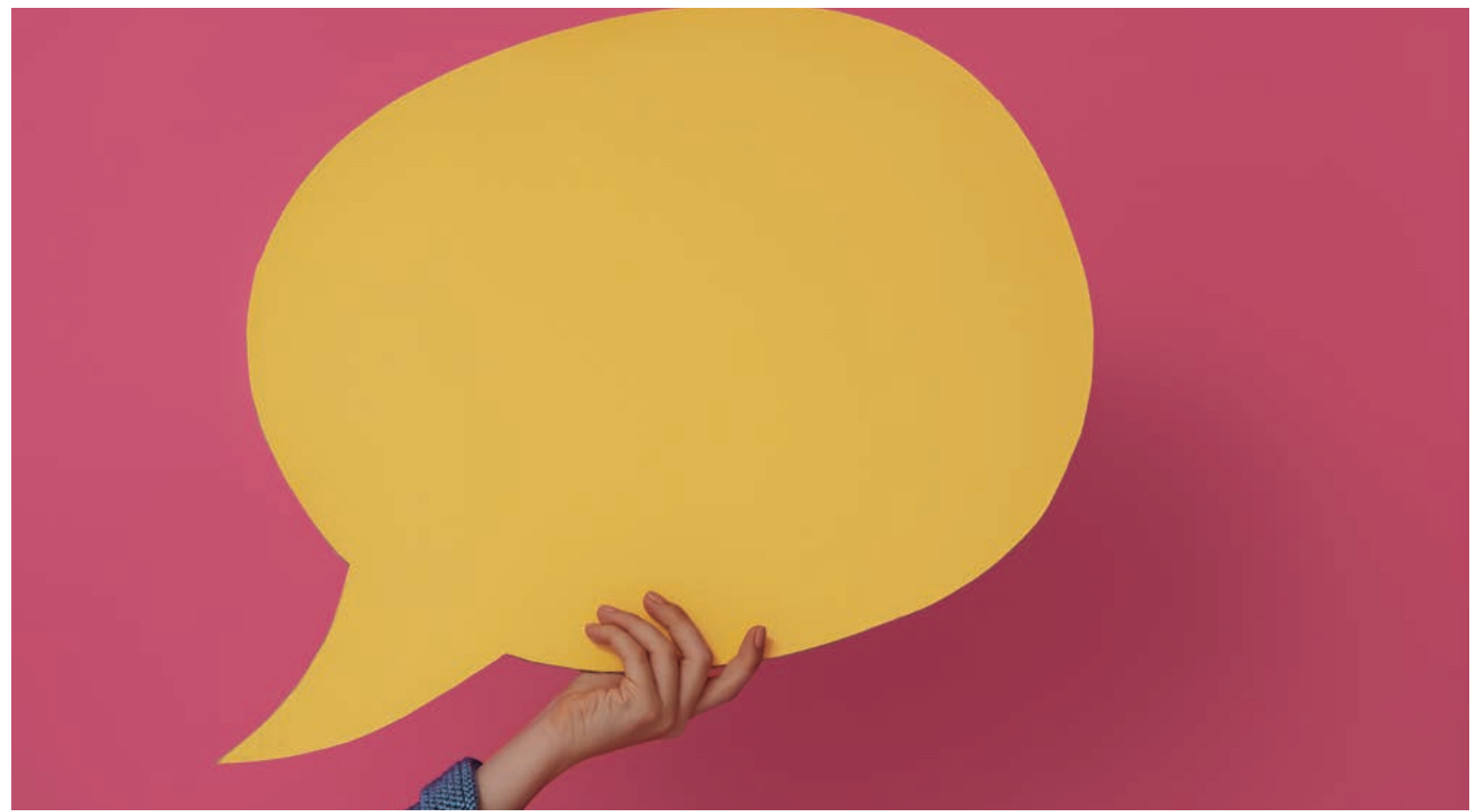

\section{La metacognición de la entrevista}

Si queremos avanzar como escuela en este proceso, necesitamos darnos un tiempo para pensar sobre lo vivido, desgranarlo y verlo en su totalidad. Si no hacemos esta parada, probablemente nos quedemos en un eco solo subjetivo de la reacción de la familia, o de la nuestra, lo cual será claramente impreciso y no nos ayudará a enfocar sucesivas entrevistas.

\section{Abordaje de situaciones complejas}

\section{La actitud del educador/orientador}

Lo esencial es poder permanecer con la familia acompañando lo que la situación trae consigo. Que la familia y nosotros podamos percibir que estamos presentes acogiendo lo que llega en el momento, sin huir, juzgar o culpabilizar. Estar al lado, no enfrente. Algunas claves que pueden servirnos de apoyo:

入 Lenguaje más sugerente, inspirador que aleccionador o sentencioso.

入 Lenguaje que no evalúa, indaga o califica.

入 Atentos a nuestra metacomunicación, es el lenguaje no verbal quien lo dice "todo".

入 Apoyarnos en un lenguaje externalizador que no pone el problema en la identidad de la persona, en un "déficit" o en algo intrínseco ("ser vago"); se tra-

\section{Por más que queramos naturalizar el momento de una entrevista familiar, no deja de ser una situación delicada en la que debemos ajustarnos lo mejor posible... si no somos muy conscientes de lo artificial de este acto, rápidamente la entrevista puede convertirse en una "estresvista"}

ta más bien de algo externo a la propia persona que circunstancialmente se ha apropiado de ello.

7 Como educadores debemos hablar desde nosotros, no como "poseedores de una verdad explicativa".

入 Ofrecer una explicación saludable, donde las personas queden "cuidadas" aunque no lleguemos a un acuerdo y terminemos en confrontación. Asumimos que no "nos hemos entendido".

\section{Preguntas que ayudan}

En algunas situaciones de las entrevistas, por la complejidad del problema, parece que todo se oscurece y no vemos más. Algunas pistas para realizar preguntas abiertas podrían ser:

7 Punto de vista temporal: ¿en qué momento empezó a ocurrir? ¿Qué otras cosas pasaban en ese momento? 


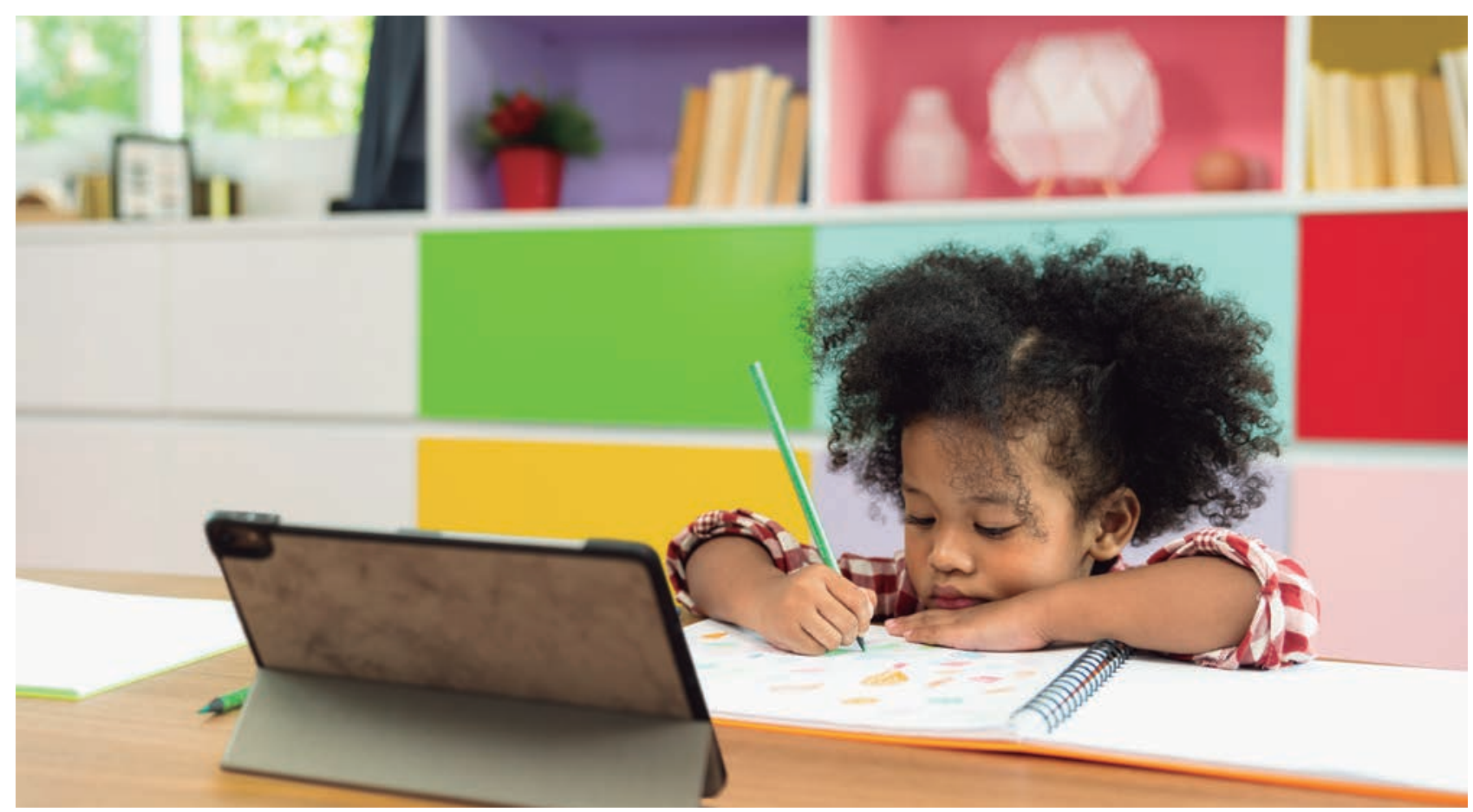

En este enfoque el alumno es realmente el centro

de todo lo que ocurre, es quien puede tener la

llave del cambio, pero no solo en la relación

familiar, sino también de la propia escuela

¿Qué sería lo peor que podría pasar? ¿Qué pasaría en el entorno si se resolviera?

7 Punto de vista de las soluciones, ¿cuáles han sido las soluciones intentadas? ¿Cuándo no ocurre el problema? ¿Qué cosas pasan cuando no sucede?

7 Punto de vista del rol, la organización, las relaciones y la comunicación dentro del sistema. ¿Cómo se relaciona este problema con nuestra familia, nuestra aula, nuestro equipo? Si no estuviese, ¿qué pasaría...?

入 Pensar la realidad desde un observador externo: ¿qué pensaría un compañero? ¿Qué vería o diría un observador externo de toda esta situación?

入 Posibles beneficios de la situación: ¿cuál es la intención positiva? ¿Qué beneficios consigue el problema? ¿A qué problema está dando solución el propio problema?

\section{Otros recursos}

Líneas de vida para que el alumno explore procesos, dibujos o metáforas que nos hagan manejable el problema, uso de figuras que representan imágenes mentales sobre cómo funciona una situación, focusing para introducir el campo de las sensaciones corporales acerca de los conflictos...

\section{Los silencios}

En las entrevistas hay que contar con "espacios en blanco". El silencio en ocasiones expresa la necesidad de pensar despacio; otras, tiene que ver con momentos emocionales especialmente intensos que necesitan pausa, también puede deberse al ritmo que necesita cada persona en un proceso de reflexión compartido.

Para mantenerse escuchando activamente debemos apreciar el silencio y no completarlo con nuestras palabras.

\section{La voz del alumno}

Tradicionalmente la entrevista familiar de la escuela tenía un carácter informativo y excluía a los alumnos. Como dijimos más arriba, en este enfoque el alumno es realmente el centro de todo lo que ocurre, es quien puede tener la llave del cambio, pero no solo en la relación familiar, sino también de la propia escuela, si somos capaces de escuchar en su propio lenguaje las barreras o las facilidades que 
sienten para su presencia, su participación y su progreso, no solo en su aprendizaje, sino en su "ser en la escuela".

\section{Algunas claves para generar cambio}

De modo telegráfico, ten en cuenta estas claves que te ayudarán a triunfar en este contexto:

$\boldsymbol{\lambda}$ La familia que tienes delante te necesita. Tener una buena experiencia contigo será algo que no olviden. Lo contrario también...

$\boldsymbol{7}$ Céntrate en hacer las cosas bien. A veces solo pensamos en cumplir nuestros objetivos, en lograr cambios, en cambiar las cosas... y olvidamos hacer las cosas como queremos hacerlas, desde nuestra identidad.

$\boldsymbol{\lambda}$ Busca investigar, compartir, comprender y ayudar a comprender. Cualquier juicio que hagas tampoco se olvidará...

$\lambda$ No olvides nunca el protagonismo central del alumno, no lo relegues, confía en él.

$\boldsymbol{\lambda}$ Buscamos cambiar un relato, que aquello que se ha construido como problema adquiera un valor diferente que posibilite un cambio. No siempre las cosas son como parecen.

7 Pregúntate qué problema está resolviendo el problema al que te enfrentas. Los conflictos no nacen de la nada.

- Te ayudará a no juzgar hablar siempre desde ti. Tú piensas, crees, sientes, escuchas, te parece...

त No tengas prisa, no busques precipitar nada, ten paciencia, da tiempo...

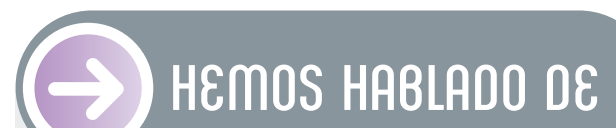 \\ Entrevista familiar; enfoque sistémico; ciclo vital familiar; escucha activa; voz del alumno.}

Este artículo fue solicitado por PADRES Y MAESTROS en mayo de 2020, revisado y aceptado en octubre de 2020.

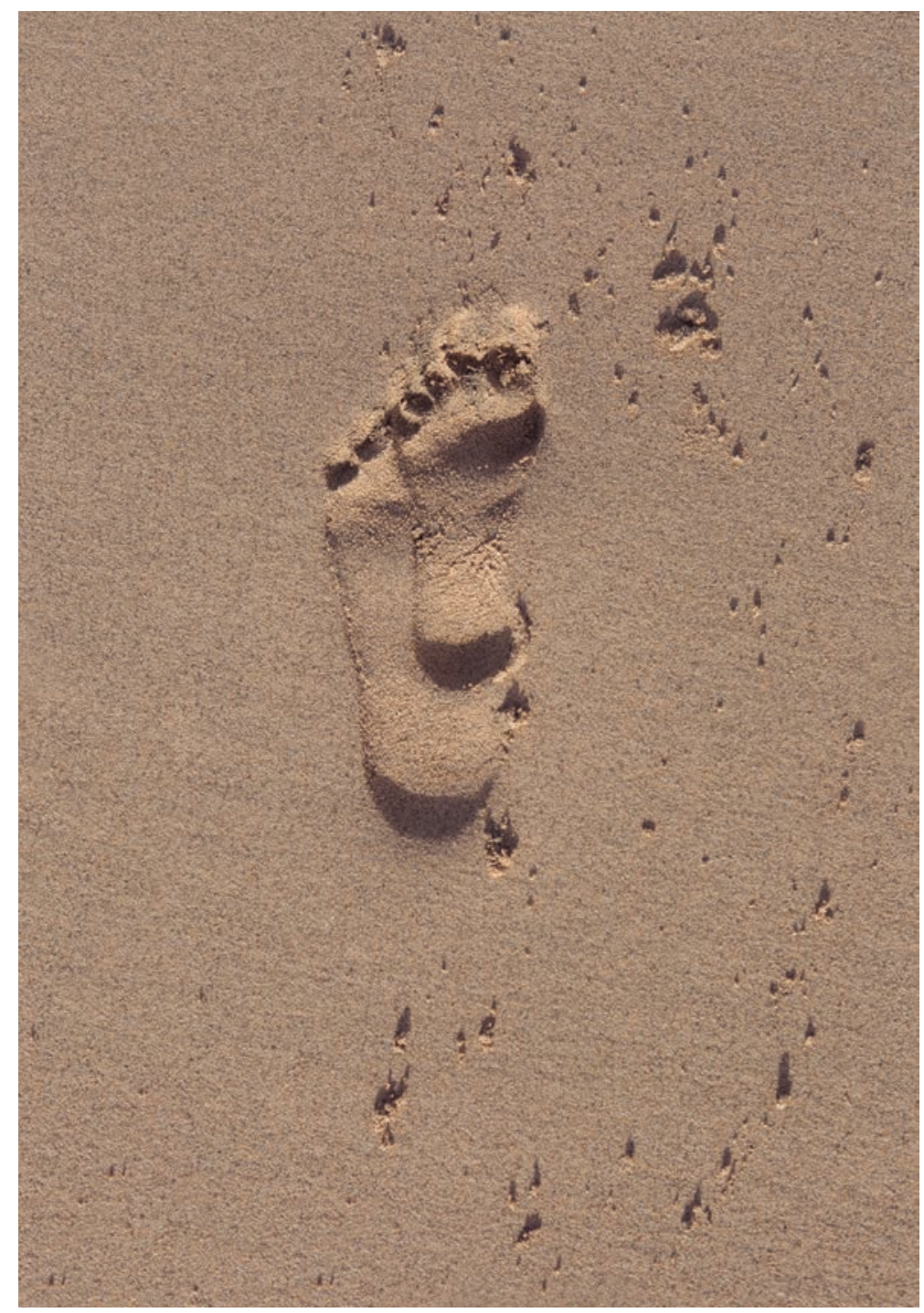

7 Cuida todos los rituales. Dan seguridad y son signo de tus valores.

入 Los cambios sistémicos suelen empezar por pequeños logros, a veces microcambios. Busca pequeños cambios que cambien la energía y la identidad problemática de quien los vive. Todo lo demás llegará solo •

\section{(DA) DARA SABER MÂS}

JuUL, J. (2017). Líderes de la manada. Cómo guiar a la familia con ternura. Barcelona: Herder.

Herrero de la Vera, M., y Beyenbach, M. (2018). Intervención escolar centrada en soluciones. Barcelona: Herder.

Maturana, H., y Dávila, X. (2015). El árbol del vivir. Chile: MVP. 